\title{
Educação física, saúde e multiculturalismo em tempos de covid-19: uma experiência no ensino médio
}

\section{Physical education, health and multiculturalism in covid=19 times: a high school experience}

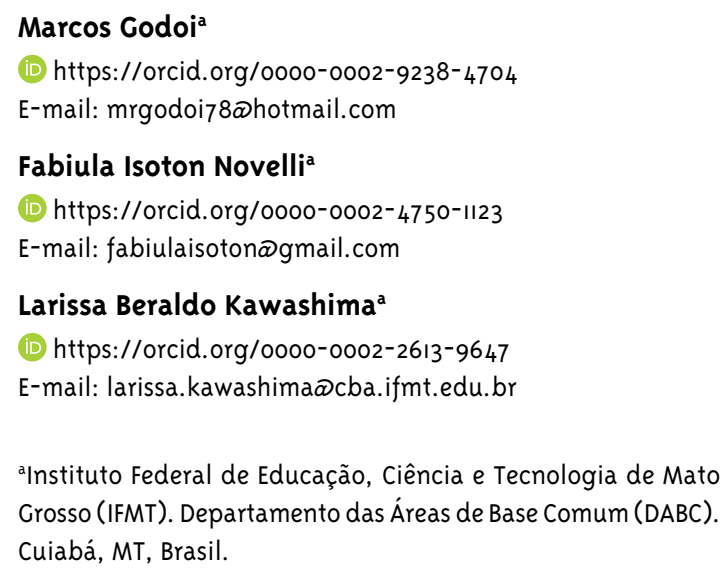

anstituto Federal de Educação, Ciência e Tecnologia de Mato Grosso (IFMT). Departamento das Áreas de Base Comum (DABC). Cuiabá, MT, Brasil.

\section{Correspondência}

\section{Resumo}

Este relato de experiência descreve e analisa o projeto de ensino "O que podem os corpos em tempos de pandemia?" desenvolvido com turmas do $1^{\circ}$ ano do ensino médio integrado ao curso técnico em Eventos, do Instituto Federal de Mato Grosso no âmbito da disciplina Educação Física, durante a pandemia da covid-19. A proposta de ensino foi baseada nos estudos culturais e no multiculturalismo, abordando os seguintes temas: conceitos de saúde; dicas para manter a saúde física e mental durante a pandemia; vulnerabilidades de indígenas, negros, mulheres e população LGBTQIA+ na pandemia e imagem corporal. Este projeto abordou temas sociais relevantes, promoveu uma maior utilização das tecnologias digitais no processo de ensino-aprendizagem, bem como estimulou a produção cultural dos estudantes.

Palavras-chave: Educação Física; Saúde; Pandemia; Ensino; Multiculturalismo. 


\section{Introdução}

This experience report describes and analyses the remote teaching project "What can bodies do in times of pandemic?" developed with classes from the $1^{\text {st }}$ year of High School integrated to the technical course in Events, from the Federal Institute of Mato Grosso (FIMT), within the scope of the Physical Education discipline during the covid-19 pandemic. We rely on Cultural Studies and multiculturalism to develop our teaching proposal. The topics covered were: health concepts; tips for maintaining physical and mental health during the pandemic; vulnerabilities of indigenous, black, women and LGBTQIA+ population in the pandemic; and body image. Despite the difficulties encountered, this project addressed relevant social issues, promoted greater use of digital technologies in the teachinglearning process, as well as stimulated the students' cultural production.

Keywords: PE; Health; Pandemic; Teaching; Multiculturalism.
Vários países adotaram medidas de distanciamento social ou até mesmo lockdown para o controle epidemiológico da pandemia do novo coronavírus, denominado SARS-CoV-2 (causador da doença covid-19). Segundo a Unesco (2020), entre as medidas adotadas estão o fechamento de instituições escolares em um determinado período ou outro da pandemia. No Brasil, o fechamento de escolas e universidades afetou mais de 52 milhões de estudantes, em consulta realizada no dia 11 de maio de 2020 (Unesco, 2020).

No Instituto Federal de Educação, Ciência e Tecnologia de Mato Grosso (IFMT), campus Cuiabá, as aulas presenciais foram interrompidas no dia 16 de março de 2020. Em seguida, foi criado um comitê para discutir a situação da pandemia e orientar professores e estudantes sobre as atividades de ensino. Na época, foi sugerida a continuidade do ensino de forma remota, utilizando as tecnologias digitais de informação e comunicação (TDIC).

Deste modo, os professores de educação física do ensino médio do IFMT elaboraram um projeto de ensino intitulado "O que podem os corpos em tempos de pandemia?", que foi desenvolvido com turmas do $1^{\circ}$ ano do curso técnico em Eventos integrado ao ensino médio que atende 76 estudantes. Este projeto apoiouse nos estudos culturais (EC) e no multiculturalismo.

Os EC ampliam a compreensão do fazer pedagógico, buscam analisar a gama de lugares diversificados e estratificados de aprendizagem, tais como mídia, cultura popular, cinema, publicidade, comunicações de massa etc. (Giroux, 2001), assim como têm um forte compromisso com as minorias, como os negros, as mulheres, os indígenas, as lésbicas, os gays, bissexuais, transexuais, queer, intersexo, assexual e outras variantes da sexualidade e de gênero (LGBTQIA+), os moradores das periferias, as pessoas de baixa renda ou desempregadas, preocupando-se com o cotidiano das pessoas e com as formas pelas quais as práticas culturais falam sobre a vida e suas vidas. Além disso, compreendem que as lutas em relação ao poder devem interagir e operar com as práticas culturais, da linguagem e da lógica do povo (Nelson et al., 2001).

Por sua vez, o multiculturalismo defende a inserção dos conhecimentos populares no currículo, 
buscando a reconfiguração do conhecimento oficial. 0 ensino multicultural deve considerar seriamente a vida dos estudantes, abrindo espaços para a diversidade de etnias, classes sociais e gênero das populações estudantis e as formas pelas quais suas identidades se interrelacionam com as manifestações populares (Mclaren, 1997; Neira, 2007).

Neste sentido, este relato de experiência teve como objetivo descrever e analisar o projeto de ensino "O que podem os corpos em tempos de pandemia?", desenvolvido pelos professores de educação física no ensino médio do IFMT, no período de afastamento social devido à pandemia da covid-19.

\section{Caminho metodológico}

O projeto "O que podem os corpos em tempos de pandemia?” foi elaborado a partir da percepção de que seria importante abordar temas relacionados à pandemia da covid-19. O período de aplicação do projeto compreendeu o primeiro bimestre de 2020 , entre 12 de junho e 14 de agosto de 2020 , sendo ministradas ao total oito aulas duplas, com a duração de 1 h 40 min.

Ao longo dessas aulas, utilizamos diferentes estratégias metodológicas: aulas on-line (síncronas) e atividades assíncronas na plataforma Google Sala de Aula, tempestade de ideias, discussões em grupo, mesa-redonda com convidados externos, trabalhos individuais e em grupo e a produção dos estudantes, que elaboraram textos, vídeos e seminários. Desse modo, para escrever este relato de experiência, consultamos os vídeos das aulas, os materiais pedagógicos utilizados e os trabalhos desenvolvidos pelos estudantes, sendo que as aulas não foram descritas em sua totalidade, apenas suas sínteses. Utilizamos a plataforma Google Meet para as aulas síncronas (on-line e em tempo real) e o Google Sala de Aula para as atividades assíncronas (on-line, mas não ocorre em tempo real).

Para tanto, organizamos este relato de experiência da seguinte forma: primeiro apresentamos a descrição das primeiras aulas e a fase de experimentação e descobertas no ambiente virtual; em seguida, a mesa-redonda com o tema do projeto; depois descrevemos alguns trabalhos dos estudantes e seu papel de produtores culturais; posteriormente, apresentamos o seminário sobre imagem corporal “cuidados e os riscos à saúde”. Por fim, apresentamos nossas considerações finais acerca dessa experiência de ensino remoto na disciplina de educação física no ensino médio.

\section{As primeiras aulas: uma fase de experimentação e descobertas no ambiente virtual}

No início de cada aula iniciamos com a acolhida dos estudantes, conversando sobre como se sentiam naquele momento, estabelecendo assim interação, comunicação empática e amorosa, no sentido freireano, ou seja, conquista implícita no diálogo pelos sujeitos dialógicos, materializada no afeto e no compromisso com o outro por meio da solidariedade e humildade (Freire, 1987).

Em 12 de junho de 2020 ocorreu a primeira aula, na qual apresentamos o planejamento bimestral do Regime de Exercício Domiciliar (RED) ${ }^{1}$ e a plataforma on-line para os estudantes. Em seguida, realizamos uma "tempestade de ideias" sobre o tema "saúde". Para os estudantes o termo "saúde" se refere a: bem-estar físico e mental; estar bem consigo e com seu corpo; saúde mental, física e social; tudo que envolve o corpo.

Também mostramos alguns conceitos sobre saúde, começando pela compreensão comum de que saúde pode ser entendida como ausência de doenças. Além disso, para numerosas famílias, "saúde" significa não poder adoecer, o que acarreta uma série de consequências como o medo de perder o emprego ou de estar na extrema pobreza (Luz, 2007).

Em seguida, trazemos o que estabelece a Organização Mundial da Saúde (1978), que definiu a saúde como a situação de perfeito estado de bemestar físico, mental e social. Porém, este conceito é complexo, pois é utópico, inatingível, pouco dinâmico e tem caráter subjetivo. Como destaca Freitas (2007), é difícil conseguir, o tempo todo, atender ao completo bem-estar nas três dimensões sugeridas.

\footnotetext{
1 A forma que o IFMT adotou para desenvolver as aulas remotas no período de distanciamento social foi regulamentada por meio do RED, que contém as normas para o ensino nesse período excepcional.
} 
Apresentamos também outros conceitos sobre saúde, como o elaborado no âmbito da VIII Conferência Nacional de Saúde:

[...] Em seu sentido mais abrangente, a saúde é resultante das condições de alimentação, habitação, educação, renda, meio ambiente, trabalho, emprego, lazer, liberdade, acesso e posse da terra e acesso a serviços de saúde. (Brasil, 1986, p. 4)

E também o conceito elaborado por Madel Luz (2007, p. 102-103):

O esporte, a dança, o namoro, as relações sexuais, o alimentar-se, o caminhar, o trabalhar, tudo pode e deve ser visto como prática de saúde. Ou de risco de doença, dependendo da intenção, da intensidade, da frequência e da quantidade que é feito. Pois todas as atividades devem ser praticadas com equilíbrio, comedidamente, isto é, sem excessos.

Depois explicamos que, apesar das divergências entre os pesquisadores em relação ao conceito de qualidade de vida, há um consenso em três pontos: a existência de aspectos objetivos e subjetivos; construto multidimensional; e presença de aspectos negativos e positivos. Nesse sentido:

Qualidade de vida é definida pela percepção do indivíduo sobre sua posição na vida, no contexto da cultura e dos sistemas de valores nos quais ele vive, e em relação a seus objetivos e expectativas, padrões e preocupações. (The WHOQOL Group, 1994, p. 28)

Segundo Martin e Stockler (1998), esse conceito pode ser definido como a distância entre a expectativa e a realidade, sendo que quanto menor a distância, melhor a qualidade de vida. Ademais, é a condição humana resultante de um conjunto de parâmetros individuais (hereditariedade e estilo de vida) e socioambientais (moradia, transporte, segurança, assistência médica, condições de trabalho, educação e lazer), que caracterizam as condições em que vive o ser humano. É importante destacar que alguns desses aspectos ou parâmetros são modificáveis, outros não.

Ao longo da aula, tentamos fazer com que os estudantes refletissem sobre como a pandemia afetou o mundo em relação à saúde, qualidade de vida e bem-estar. Além disso, tal qual o conceito de saúde, os conceitos de qualidade de vida e de bemestar também foram problematizados, buscando promover a reflexão nos alunos que abrangesse os aspectos sociais e econômicos, principalmente nas pessoas de baixa renda ou sem renda.

Em 19 de junho ocorreu a segunda aula, na qual abordamos o tema "saúde mental". Iniciamos com uma "tempestade de ideias", tendo como resultado: "bem-estar mental; uma cabeça livre; equilíbrio emocional; controle emocional; ter um psicológico bom; Netflix, doces e jogos; controle emocional; cuidado; controle; sanidade; equilíbrio psicológico; estar bem equilibrado consigo mesmo, sentimentalmente, psicologicamente, estar em paz; autoestima; aceitar as exigências da vida”.

Depois discutimos sobre a pandemia da covid-19 e seus impactos, como mudança de hábitos, distanciamento social, ansiedade, depressão, entre outras questões que afetam a saúde mental.

A próxima atividade foi uma dinâmica de autoestima sugerida pelo projeto Saúde e Prevenção nas Escolas (Brasil, 2006), na qual solicitamos como material uma folha de papel para que pudessem rasgá-la. Explicamos que leríamos uma lista de situações que poderiam causar prejuízo à autoestima e, cada vez que fosse lida uma frase, eles deveriam rasgar um pedaço da folha. Por exemplo:

"Imagine que você se olhou no espelho e se achou horrível. Seu chefe criticou publicamente o seu desempenho no trabalho. Um grupo de colegas estava conversando [...] você escutou só a seguinte frase: 'Mas naquele bairro... (era o bairro onde você mora) só tem bandido e vagabundo!' [...]”. (Brasil, 2006, p. 29)

Ao final da leitura, os estudantes foram estimulados a refletir se e por que todas as situações afetariam a autoestima deles, bem como o que mais afetaria a autoestima deles e por quê. Na segunda etapa, fizemos a leitura de um novo conjunto de situações: à medida que a situação ajudasse a melhorar a autoestima, deveriam reconstruir a folha de papel com os pedaços rasgados. Foram levantadas as seguintes questões: "O que mais contribuiu para a recuperação da sua autoestima? 
Você conseguiu recuperar toda a autoestima perdida? Você consegue imaginar outra situação que seria valiosa para aumentar sua autoestima?”.

Os estudantes verbalizaram situações que mais causariam baixa autoestima: ouvir críticas da família e receber pouco apoio; medo de sofrer discriminação ou ser humilhado por diferenças de classe ou raça/etnia; sentimento de inferioridade e pressões para se enquadrar ao padrão estético; inquietação em relação às imagens de "perfeição" corporal nas redes sociais; e sentimento de se sentir excluído ou ter sofrido bullying na escola. Além disso, emergiram falas que defendiam a importância de conversar, conhecer e se colocar no lugar do outro para uma convivência de maneira fraterna.

Em seguida, exibimos dois vídeos, o primeiro mostrava uma criança branca brincando de passar barro no corpo, tendo como título "Cansei de ser branco". Para a discussão, explicamos que ninguém nasce racista, mas aprende a ser racista dependendo do meio em que vive, sendo também possível aprender a não ser racista. No segundo vídeo, exibimos uma propaganda da marca de cerveja Skol (Comercial..., 2017) com o intuito de discutir a diversidade de corpos. Destacamos a influência das mídias em relação aos estereótipos de raça e de beleza, que atualmente têm incorporado o discurso da diversidade em propagandas, filmes e desenhos.

A esse respeito, vejamos dois comentários dos estudantes na aula:

Eu acho necessário [a representação de negros na mídia], porque para quem tem uma pele clara isso não importa, é uma pessoa que não se sente fora da sociedade. Para as pessoas que são pretas $e$ veem, eles falam: "Meu Deus! Pela primeira vez eu consigo me ver numa posição de alguém que está sendo visto pela sociedade como uma pessoa comum ou não inferior às outras pessoas”. (Estudante P.)

[...]. Por exemplo, o comercial de cerveja agora está mudando, mas antes era aquele padrão de mulheres brancas, loiras e totalmente machista. $\varepsilon$ não tem que ser assim, necessariamente. É como se fosse uma ilusão que nós mesmos criamos $e$ depois criticamos. $\varepsilon$ muito contraditório e muita hipocrisia da parte de todos nós. A gente critica tanto a sociedade, mas quem é a sociedade? Somos nós, nós fazemos a sociedade. Os padrões e o nosso jeito de ver o mundo vai mudar, quando a gente começar a mudar de dentro. Porque se a gente não começar a falar o que a gente pensa sobre essas coisas e agir de acordo com o que pensa, só assim a gente vai mudar a sociedade. Então a gente deveria parar um pouco de falar e agir bem mais [...]. (Estudante AC)

Os depoimentos revelam o posicionamento dos estudantes em relação às imagens e estereótipos na mídia, bem como a importância da diversidade de representações. Adquirir uma leitura crítica da cultura popular e da mídia envolve aprender habilidades de desconstrução, de compreensão de como os textos culturais funcionam, significam e influenciam as pessoas (Kellner, 2001), deste modo, há uma educação crítica e emancipatória.

Ainda nesta aula, exibimos o vídeo "Ansiedade e crise do pânico na pandemia: como se acalmar?", do psiquiatra Jairo Bouer (Ansiedade..., 2020), destacando que a covid-19 é uma doença que merece atenção dos jovens também. Conforme explica nesse vídeo, o pico de ansiedade de muitas pessoas durante a pandemia é diferente de um grau de ansiedade normal.

Ansiedade é uma apreensão, vocêfica mais atento, um pouco mais ligado em tudo que está acontecendo. Isso gera um pouco de agitação, um pouco de desconforto, mas é uma situação controlável. $\varepsilon$ diferente do pico de ansiedade, que pode demorar 15, 30 minutos, até uma hora e em que a pessoa se sente muito mal. É uma sensação de morte iminente ou de perda de controle, taquicardia, sudorese, falta de ar. [...]. (Ansiedade..., 2020, 2'o7”)

Bouer também apresenta algumas dicas para controlar a ansiedade: (1) organizar uma rotina para criar uma sensação de normalidade nessa "nova ordem"; (2) desfocar, tentar se concentrar em alguma atividade que deixa a pessoa um pouco mais tranquila (exemplos: ver uma série de TV, ler um livro, meditar); (3) tentar controlar o fluxo de informação; (4) não se isolar emocionalmente, mas buscar contatar os amigos e redes de apoio; 5) procurar ajuda profissional se a situação se agravar. 
Concordamos com Armour et al. (2020) ao sustentar a ideia de que os professores de educação física precisam ampliar as habilidades digitais, críticas e éticas existentes, devendo aproveitar o potencial educativo das tecnologias digitais e sites de mídia social de saúde. Dessa maneira, tentamos aplicar esse conceito ao longo deste projeto.

É importante destacar que as primeiras aulas deste projeto de ensino constituíram-se como uma fase de experiência e de descoberta do ambiente virtual, uma vez que foi a primeira vez que, nós professores, estávamos ensinando, de forma remota e emergencial, utilizando as tecnologias digitais. Inicialmente estávamos um pouco apreensivos, mas com o tempo começamos a nos adaptar a essa forma de ensino.

\section{Mesa-redonda: "O que podem os corpos em tempos de pandemia?"}

Em 26 de junho de 2020 ocorreu a terceira aula, tendo como base os acontecimentos históricos e do cotidiano que aconteceram durante a pandemia da covid-19, envolvendo episódios de racismo, violência e vulnerabilidade de mulheres, indígenas e população LGBTQIA $+^{2}$, organizamos uma mesa-redonda on-line com o tema: "O que podem os corpos em tempos de pandemia?: riscos, vulnerabilidades e resistências".

Sobre o conceito de vulnerabilidade, Ayres et al. (2006) explicam que a vulnerabilidade individual refere-se à qualidade de informações sobre determinada doença e a capacidade de se prevenir. A vulnerabilidade social está relacionada a fatores contextuais que influenciam a vulnerabilidade pessoal; já a vulnerabilidade institucional tem a ver com a capacidade de resposta das instituições públicas no enfrentamento e superação das doenças (Ayres et al., 2006).

Para conversar com os nossos estudantes, convidamos Marcos Terena, liderança indígena, Julianne Caju de Oliveira Souza Moraes, jornalista e professora negra, e Clovis Arantes, militante LGBTQIA+. Marcos Terena relatou sua trajetória de militante indigenista no Brasil e no exterior. Em relação à situação dos povos indígenas durante a pandemia, destacou que assim como muitas comunidades do interior do Brasil, eles não sabiam o que era a covid-19, nem como se proteger dessa doença; criticou a política de governo que não tem uma diretriz clara em relação ao novo coronavírus, bem como a falta de orientações da Fundação Nacional do Índio (Funai) e da Secretaria Especial de Saúde Indígena, que contribuem negativamente para a situação de vulnerabilidade dos povos indígenas.

Terena relatou o que um pajé da etnia Terena proferiu para ele depois de um incêndio na Floresta Amazônica ${ }^{3}$ que atingiu uma aldeia indígena:

"Agora que esses homens colocaram fogo na floresta, a onça não tem mais onde tomar água, o macaco não tem mais onde dormir, destruíram a casa dos animais. Então agora que derrubaram a floresta vai vir o vento e vai trazer castigo para essas pessoas, uma doença que nós não conhecemos e vai matar muita gente". Por coincidência ou por uma profecia indígena, esse tempo chegou, a chamada pandemia. ${ }^{4}$ (Informação verbal)

Julianne Moraes discorreu que encontros como este são importantes para refletir sobre os problemas sociais, mas também para apontar soluções, para "esperançar" no sentido freireano, ou seja, de não desistir, de levantar e ir adiante, de juntar-se com outros para fazer um outro mundo possível (Freire, 1997). Em seguida, questionou:

Como estão os corpos das mulheres, das empregadas e das desempregadas, das autônomas, das donas de casa e das funcionárias de empresas privadas e públicas nesse momento de pandemia? Quais os desafios, quais as lutas e instrumentos para manter a saúde física, mental, espiritual e financeira

\footnotetext{
2 Por exemplo, a morte de George Floyd por policiais brancos nos Estados Unidos e as lutas do movimento “Black lives matter!", a falta de políticas de proteção das populações indígenas e moradores de rua no Brasil, o aumento de casos de violência contra mulheres durante a pandemia.

3 Quando fizemos esta mesa-redonda, os incêndios na Amazônia e no Pantanal não tinham se agravado tanto quanto nos meses de agosto e setembro de 2020.

4 Fala de Marcos Terena durante a aula/live de Educação Física, IFMT, em 26 de junho de 2020. Disponível em: https://bit.ly/3uJU3d4. Acesso em: 02 jun. 2021.
} 
nesse momento tão ímpar, delicado e complexo? (Informação verbal)

Ela destacou que a pandemia não se manifesta da mesma maneira nos grupos e classes sociais argumentando que as mulheres fazem parte de um grupo de grande vulnerabilidade. Para tanto, cita alguns dados: a pobreza afeta principalmente a população preta ou parda $(38,1$ milhões de pessoas), sendo que deste grupo 27,2 milhões são mulheres (Nery, 2019). o trabalho informal é realizado por $41,1 \%$ da população brasileira, sem direitos trabalhistas garantidos, e as mulheres são as mais afetadas (Sudré, 2020); 92\% das trabalhadoras domésticas são mulheres em sua maioria negras, com baixa escolaridade e renda (Ipea, 2019); enquanto a população feminina trabalha em tarefas domésticas 21,7 horas semanais, a população masculina dedica apenas 11 horas/semana (Gandra, 2020); as mulheres são quase $85 \%$ do setor de enfermagem (cuidadores de idosos, enfermeiros, técnicos e auxiliares de enfermagem) (Alessi, 2020); e 45,6\% dos profissionais da medicina no Brasil são mulheres (Proporção..., 2018).

Outro aspecto destacado é que a produtividade feminina durante a pandemia diminuiu e o teletrabalho fez com que passassem mais tempo em tarefas domésticas. Isso também se deve ao machismo e patriarcado na nossa sociedade, em que muitos homens "até querem ajudar mais", mas se sentem intimidados por essa cultura. Além disso, durante a pandemia houve um aumento da violência doméstica e do feminicídio (ONU, 2020), pois ficar em casa em isolamento, para muitas mulheres, significa também estar trancada com seu próprio agressor.

A pandemia escancarou as mazelas humanas da sociedade brasileira, mas o que fazer diante disso? Uma das soluções apontada por Julianne Moraes seria dialogar, fazer lives, conversar em família e com amigos sobre assuntos considerados tabus. Ainda, a palestrante sugeriu: refletir e ser agente de transformações; dividir tarefas domésticas; ajudar as pessoas; buscar informação, ler livros, participar de lives; buscar autoformação; seguir blogueiros e youtubers que promovem ações efetivas (por exemplo: apoio ao empreendedorismo de mulheres, startups de inovação, etc.).

O terceiro palestrante, Clovis Arantes, destacou como a pandemia intensificou a situação de vulnerabilidade dos corpos LGBTQIA+. Ser uma pessoa LGBTQIA+ expõe questões de vida, mas também de norma e de moral, pois nossa sociedade heteronormativa, racista e machista apregoa a eliminação dos corpos que não se enquadram nesse sistema. Arantes chamou atenção para o dado de que o número de pessoas LGBTQIA+ assassinadas cresceu $48 \%$ durante a pandemia segundo dados da Associação Nacional de Travestis e Transexuais (Antra, 2020). Falar desses corpos traz questões de moral e de moralidade, porque o corpo desses sujeitos foi "patologizado" ao longo da história.

Sendo assim, neste projeto buscamos romper com as culturas negadas no currículo escolar, como: as etnias minoritárias; o mundo feminino; a homossexualidade; o mundo da classe trabalhadora e das pessoas pobres. Coincidimos com Santomé (2001) que as escolas podem ser espaços de luta cultural, pois têm a missão de expandir as capacidades humanas, os processos de reflexão da realidade, desenvolver destrezas para a atuação dos estudantes na sociedade de maneira responsável, crítica, democrática e solidária.

\section{Os estudantes como produtores culturais}

Em relação aos trabalhos produzidos pelos estudantes, o primeiro foi responder um questionário sobre saúde física e mental e alimentação saudável. Disponibilizamos no Google Sala de Aula dois textos sobre a importância da atividade física para a saúde física e mental e a alimentação na adolescência, bem como dois vídeos produzidos pelo Dr. Dráuzio Varella: "150 minutos de exercícios por semana”, e "Preguiça em se exercitar", para que os estudantes respondessem o questionário. Nosso intuito foi apresentar informações que contribuíssem com a promoção da saúde dos estudantes.

\footnotetext{
5 Fala de Julianne Moraes durante a aula/live de Educação Física, IFMT, em 26 de junho de 202o. Disponível em: https://bit.ly/3uJU3d4. Acesso em: 02 jun. 2021.
} 
Outro tipo de trabalho foi a produção de vídeos. No primeiro, os estudantes elaboraram um vídeo com imagens deles próprios se exercitando. Para isso, teriam que realizar uma pesquisa prévia de práticas corporais na Internet, escolher uma e fazer sua produção. Os vídeos foram muito criativos, seja pelos cenários escolhidos, pela edição, informações sobre a prática corporal escolhida ou pela diversidade de práticas.

Nesse sentido, Goodyear e Armour (2019 apud Armour et al. 2020) destacam que as tecnologias digitais estão fazendo a diferença na saúde e bem-estar dos jovens. Um dos grandes desafios atuais é preparar os jovens para maximizar as oportunidades da era digital e minimizar os riscos. Deste modo, buscamos estimular as práticas corporais dos estudantes, aliando-as à produção de conteúdo cultural.

Outro vídeo solicitado foi sobre a temática abordada na mesa-redonda "O que podem os corpos em tempos de pandemia?" e a vulnerabilidade de indígenas, mulheres, negros e população LGBTQIA+. Os estudantes poderiam elaborar o vídeo utilizando diferentes linguagens como poesia, rap ou monólogo.

Em um dos vídeos, a estudante leu o seu poema com voz off:

Quem era para ser voz, não faz voz. Vivemos em um faz de conta e fingimos que está tudo bem. Isto soa bem? $E$ o artigo $5^{\circ}$ da Constituição que virou só um número? Quanto tempo a dor vai viajar no tempo? Será que fazemos leis para pessoas pensando em pessoas? Ou será que fingimos simplesmente em nos importar com pessoas? Uma guerra travada entre raças e etnias. Preconceitos e racismos escondidos em sua hipocrisia. Heresia? o que te faz melhor ou pior do que essa pequena burguesia? Hipocrisia e ignorância. É fato. $\varepsilon$ ouvimos coisas como: "A culpa foi dela!" $E$ então vêm as mortes e vamos examinar o posfácio: "e tu, até quando vai ouvir tudo isso calado? Seja forte e verás que tem pessoas fortes ao teu lado!". (Vídeo da estudante A)

Nesse vídeo acompanha uma música de fundo e a imagem de um desenho (Figura 1) que ela produziu para ilustrar o vídeo:

\section{Figura I - Desenho elaborado para o vídeo da estudante A.}

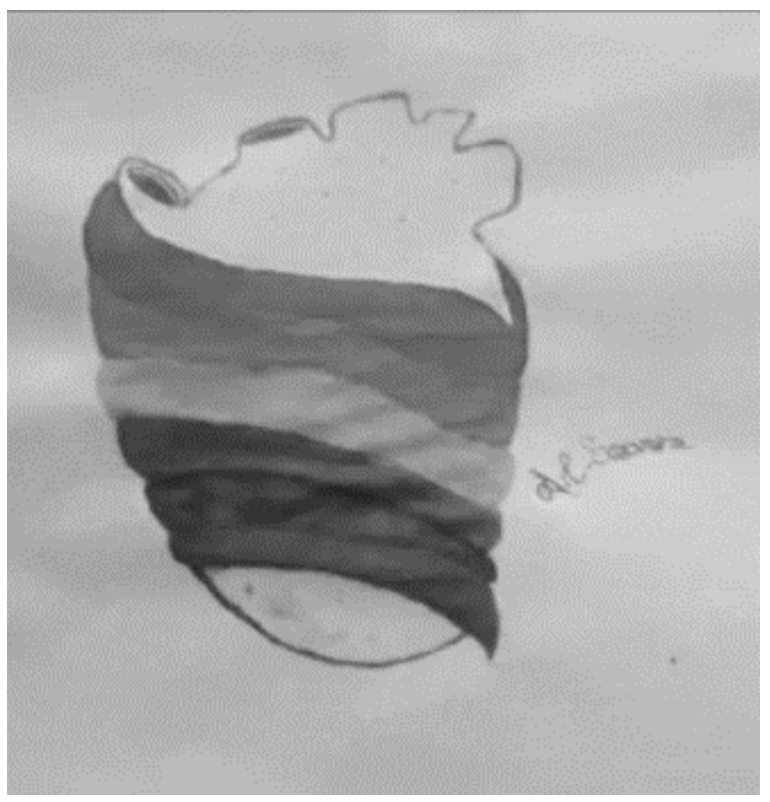

Fonte: Imagem retirada do vídeo da estudante A (2020)

No segundo vídeo, a estudante fez a leitura de um poema de sua autoria, com a voz off:

Racismo. O homem traduz na cor o que condiz com a sua raça. $O$ importante é o que se faz, seja feito com amor, como manda o criador. Nos caminhos da esperança para que a luz seja verdade, Deus criou a humanidade, a sua imagem e semelhança. O racista traz amargura, se achando no direito, todo mundo tem defeito. De pele branca ou escura, para ter a alma pura, é preciso confiança. Sem haver desigualdade, Deus criou a humanidade, a sua imagem e semelhança. o preconceito é um ato fraco, gente ignorando gente, desconhecendo parente, chama o negro de macaco. Mas vai para o mesmo buraco e os pecados para a balança. Para se ter liberdade, Deus criou a humanidade a sua imagem e semelhança. Branco, preto ou nordestino, espírita, católico ou crente, rico, pobre ou deficiente, índio, caboclo ou latino, japonês, chinês, filipino. A vida é a maior herança e amor não tem maldade. Deus criou a humanidade a sua imagem e semelhança! (Vídeo da estudante B)

Essa estudante também utilizou uma música de fundo e várias imagens, selecionamos três delas (Figura 2). 
Figura 2 - Imagens utilizadas no vídeo da estudante B.

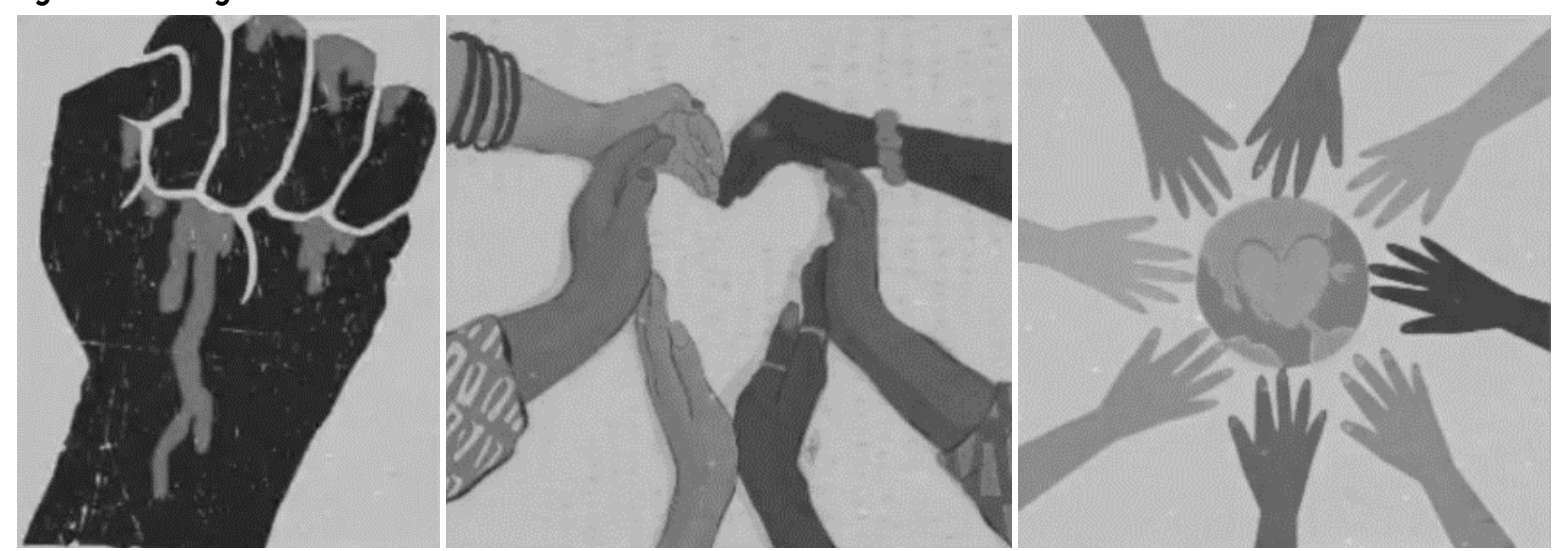

Fonte: Imagens retiradas do vídeo da estudante B (2020)

No terceiro vídeo, um estudante se gravou em preto e branco, com uma luz refletindo em seu rosto enquanto lia o monólogo:

Não é meu aniversário ou nem outro dia especial. Ontem tivemos a nossa primeira briga. Foi tão horrível, ele me disse palavras tão cruéis e tão severas que me doeram de verdade. Mas eu sei que ele está arrependido, porque hoje ele me trouxe flores. Ontem ele me bateu e me sufocou com um travesseiro. Parecia um pesadelo, mas nós sabemos que os pesadelos não são reais e que nós acordamos deles. [...]. Hoje é um dia muito especial, é o dia do meu funeral. Ele conseguiu me matar ontem à noite. Se tivesse coragem para deixá-lo ou se eu tivesse procurado ajuda profissional, hoje eu não teria recebido flores [...]. (Vídeo do estudante C)

Interessante observar seu exercício de alteridade, ou seja, um homem jovem que escreveu seu texto como se fosse uma mulher que sofre agressão de seu marido e que, ao final, fatalmente morre vítima de seu companheiro.

Nesta tarefa, os estudantes atuaram como produtores culturais, revelando o processo de reflexão sobre temas atuais e de relevância social. É importante destacar que o multiculturalismo e a pedagogia crítica buscam contestar fortemente a persistência das desigualdades de raça, gênero e classe, seja baseada na propriedade, no patriarcado ou na homofobia (Mclaren, 2001).

\section{Seminário Imagem corporal, cuidados e os riscos à saúde}

Após as férias escolares de julho de 2020, passamos a destinar um tempo da aula (em torno de 15 a 20 minutos) para a prática de alongamentos e exercícios de ioga.

Nas aulas dos dias 17, 24 e 31/o7, 7 e 14/o8 realizamos um seminário temático intitulado "Imagem corporal, cuidados e os riscos à saúde". Doze grupos (duplas ou trios) de estudantes apresentaram no seminário, e os temas abordados foram: a influência da mídia na busca pelo corpo "perfeito"; bulimia, anorexia, vigorexia, compulsão alimentar, bodybuilding, body modification, automutilação, uso de anabolizantes nas academias de ginástica, uso de doping no esporte, veganismo, meditação, gordofobia e cultura black power. Seguem algumas imagens das apresentações dos estudantes: 
Figura 3 - Slides sobre bulimia e anorexia.

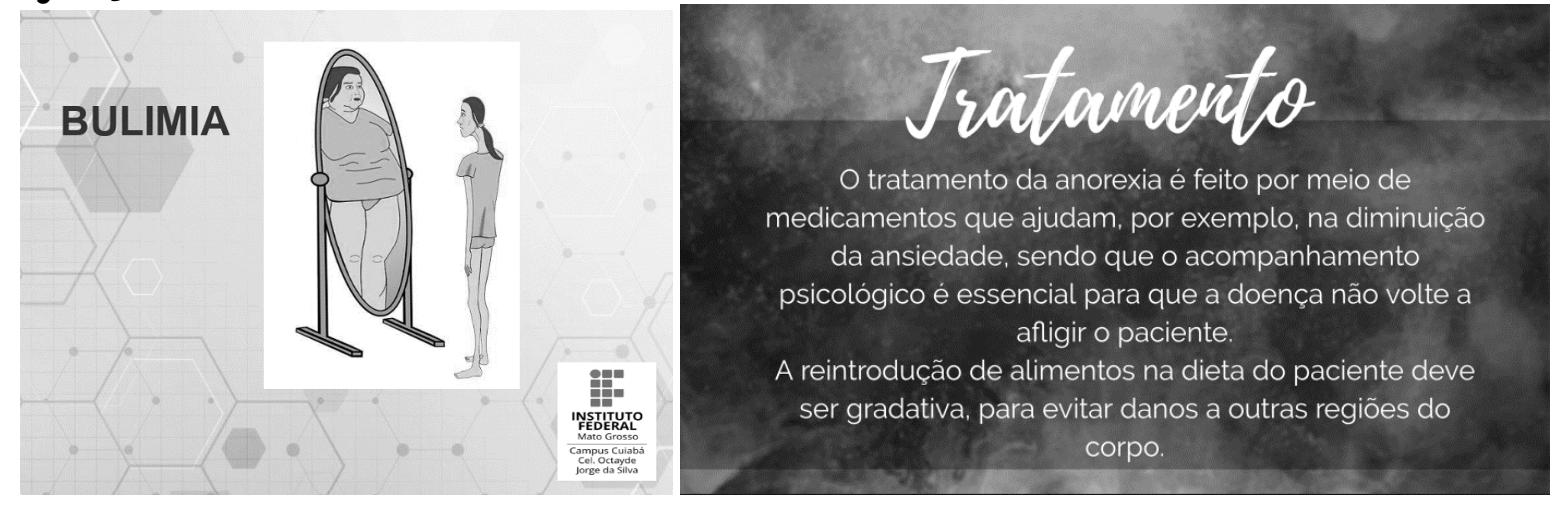

Fonte: Imagens retiradas das apresentações dos alunos no Ambiente Virtual de Aprendizagem do IFMT (2020)

Figura 4 - Slides sobre o uso de anabolizantes e a vigorexia.
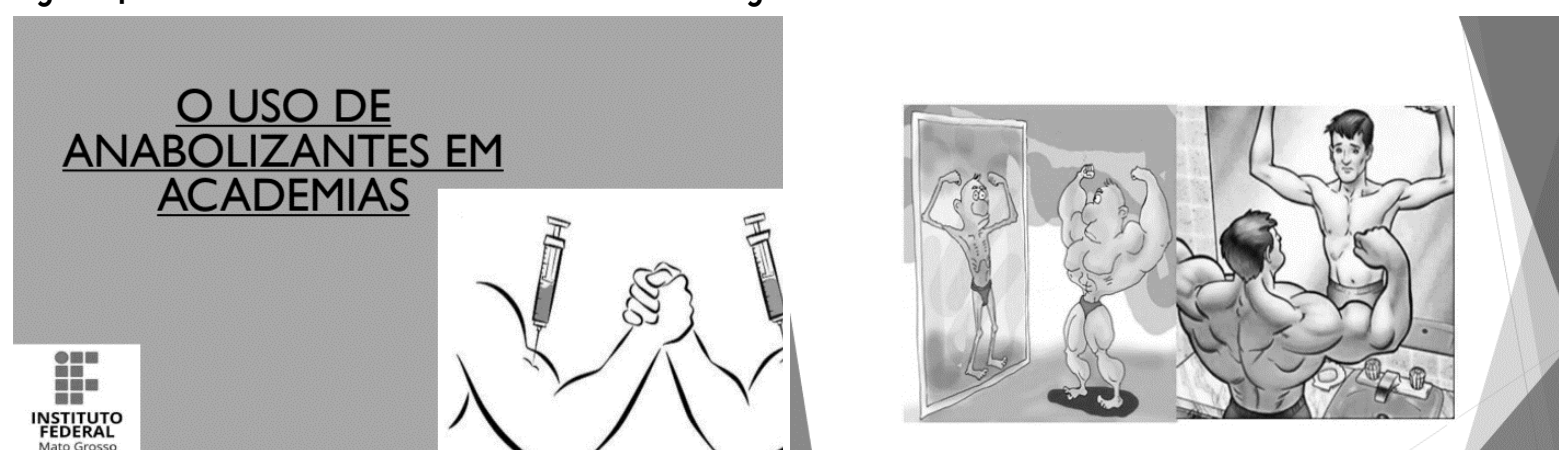

Fonte: Imagens retiradas das apresentações dos alunos no Ambiente Virtual de Aprendizagem do IFMT (2020)

Figura 5 - slides sobre gordofobia e vegetarianismo.
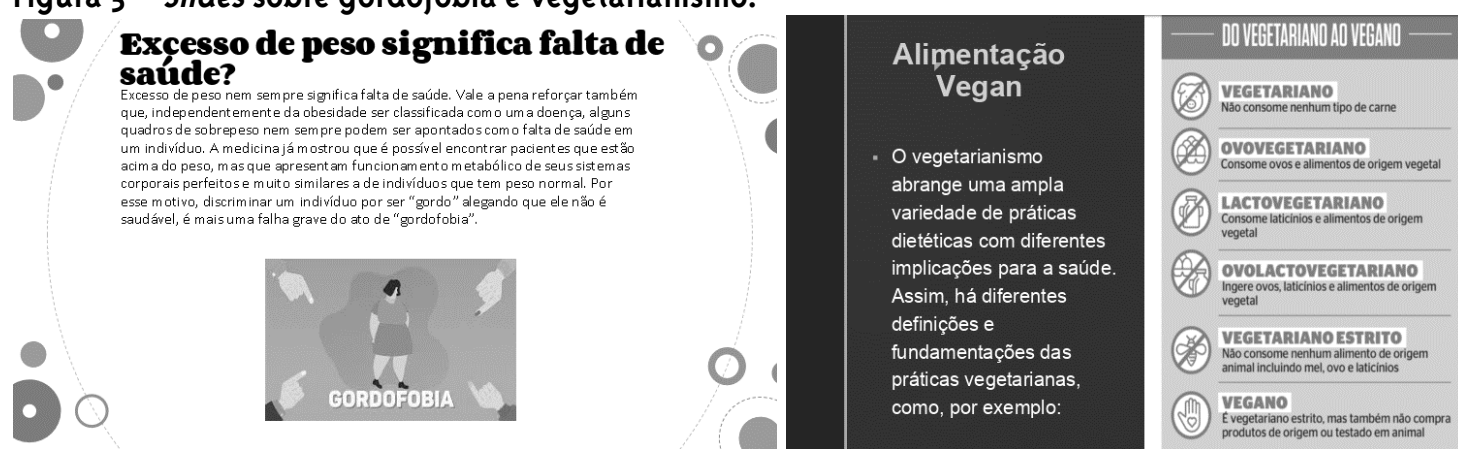

Fonte: Imagens retiradas das apresentações dos alunos no Ambiente Virtual de Aprendizagem do IFMT (2020)

Nesse seminário, os estudantes destacaram as causas, sintomas, consequências, tratamentos de transtornos da imagem corporal ou do uso de substâncias tóxicas para modificar o corpo, além de promoverem a discussão sobre preconceitos corporais e movimentos de resistência à estética hegemônica.
Após cada apresentação, abrimos para perguntas e comentários. Ficou evidente que os temas estavam relacionados às suas vidas, quando não os afetava diretamente, conheciam alguém próximo que passava por aquele problema. Eles puderam refletir sobre esses temas e se posicionar, desabafar, 
compartilhar experiências de ajuda e de superação, por exemplo, relacionadas ao racismo, aos padrões corporais ou de gênero.

\section{Considerações finais}

Neste relato de experiência apresentamos atividades realizadas remotamente com estudantes do ensino médio do IFMT, na disciplina educação física, durante o período de distanciamento social devido à pandemia da covid-19. Para encerrar as aulas do $1 .^{\circ}$ bimestre de 2020 , elaboramos o projeto de ensino "O que podem os corpos em tempos de pandemia?", desenvolvido ao longo de oito aulas duplas.

Os temas abordados nesse projeto foram: conceitos de saúde, bem-estar, qualidade de vida, riscos e vulnerabilidades; dicas para manter a saúde física e mental durante a pandemia; vulnerabilidades de indígenas, negros, mulheres e população LGBTQIA+ na pandemia; e imagem corporal. As aulas foram desenvolvidas por meio das tecnologias digitais, de maneira síncrona ou assíncrona, com atividades e tarefas que os alunos realizaram pela plataforma Google Sala de Aula. Utilizamos diferentes estratégias metodológicas nas aulas on-line, como: tempestade de ideias, discussões em grupo, mesa-redonda com convidados externos, trabalhos individuais e de grupo, produção de textos e de vídeos pelos estudantes e seminário.

Dentre as dificuldades encontradas durante essa experiência de ensino, destacamos que nem todos os estudantes participavam das aulas on-line, a participação média era de 50 a $60 \%$. No entanto, os estudantes que não conseguiam participar, poderiam consultar os materiais (vídeos e textos) e realizar as tarefas propostas na plataforma on-line $e^{6}$. Outra dificuldade foi que alguns estudantes não conseguiram anexar os vídeos na plataforma e acabaram enviando-os por e-mail ou pelo WhatsApp. Isso demandou um esforço para localizar esses trabalhos para dar feedback.

Sobre os pontos positivos dessa experiência, destacamos: maior utilização das TDIC no processo de ensino-aprendizagem; diversificação das estratégias de ensino; participação de convidados externos à instituição nas aulas/lives para dialogar com nossos estudantes; abordagem de temas sociais relevantes e produção cultural dos estudantes, desenvolvendo habilidades criativas e com o uso das tecnologias. Neste sentido, assim como Palmer (1999 apud Hooks, 2019, p. 201), compreendemos que:

[...] A educação em seu melhor - essa profunda transação humana chamada ensino e aprendizagem não é só sobre conseguir informações ou conseguir um emprego. Educação é sobre cura e integridade. É sobre empoderamento, libertação, transcendência, sobre renovar a vitalidade da vida. É sobre encontrar e reivindicar a nós mesmos e nosso lugar no mundo.

Neste sentido, mais do que formar estudantes e preparar para o mercado de trabalho, estamos formando seres humanos, que vivenciam diariamente muitos desafios em suas vidas cotidianas, ainda mais no contexto excepcional da pandemia da covid-19. Por isso, buscamos abordar temas que fossem relevantes e úteis para suas vidas.

Acreditamos que essa experiência de ensino remoto na Educação Física, inédita do ponto de vista das condições sociais, econômicas e de saúde, foi muito significativa e desafiadora tanto para nós, professores, quanto para nossos estudantes. Não desistiremos da vida, continuaremos resistindo, ensinando e aprendendo uns com os outros, com respeito, compromisso, solidariedade e fraternidade pela humanidade.

\section{Referências}

ALESSI, G. A luta contra o coronavírus tem o rosto de mulheres. El País, 2 de maio de 2020. Disponível em: < https://brasil.elpais.com/brasil/2020-05-02/ a-luta-contra-o-coronavirus-tem-o-rosto-demulheres.html>. Acesso em: 15 jun. 2020.

ANSIEDADE e crise de pânico na pandemia: como se acalmar? Boletim com Jairo Bouer. 9'49". MOV. YouTube. 2020. Disponível em: <https://bit.ly/3uLtkfW>. Acesso em: 10 jun. 2020.

6 É importante destacar que o IFMT, campus Cuiabá, lançou um edital para doar 1.50o chips para acesso à Internet e 75o bolsas de R\$̣ 1.50o para aquisição de notebooks ou tablets para alunos de baixa renda. 
ANTRA - ASSOCIAÇÃO NACIONAL DE TRAVESTIS E TRANSEXUAIS. Assassinatos de pessoas trans volta a subir em 2020. Boletim, Rio de Janeiro, n. 2, 2020. Disponível em: <https://bit.ly/3plDbrR>.

Acesso em: 15 jun. 2020.

ARMOUR, K. M. et al. The digital age challenge: preparing physical and health educators to understand and support "online" youth. In: McPHAIL, A.; LAWSON, H. A. School physical education and teacher education: collaborative redesign for the twenty-first century. Londres: Routledge, 2020. p. 91-114.

AYRES, J. R. et al. Risco, vulnerabilidade e práticas de prevenção e promoção da saúde. In: CAMPOS, G. W. S. et al. Tratado de saúde coletiva. 2. ed. São Paulo: Hucitec, 2006. p. 375-418.

BRASIL. Ministério da Saúde. $8^{a}$ Conferência Nacional de Saúde. Relatório final. Brasília, DF, 1986.

BRASIL. Ministério da Saúde. Saúde e prevenção nas escolas: guia para profissionais da saúde e educação. Brasília, DF, 2006.

COMERCIAL Skol - Skolors. 1'22”. SKOL. YouTube. 2017. Disponível em: <https://bit.ly/3pjt32L〉. Acesso em: 10 jun. 2020.

FREIRE, P. Pedagogia do oprimido. 17. ed. Rio de Janeiro: Paz e Terra, 1987.

FREIRE, P. Pedagogia da esperança: um reencontro com a pedagogia do oprimido. Rio de Janeiro: Paz e Terra, 1997.

FREITAS, F. F. A educação física no serviço público de saúde. São Paulo: Hucitec, 2007.

GANDRA, A. Mulher tem peso importante no chamado "trabalho invisível”. Agência Brasil, Rio de Janeiro, 4 jun. 2020. Disponível em: <https://bit.ly/3uL6Xav>. Acesso em: 15 jun. 2020.

GIROUX, H. Praticando estudos culturais nas Faculdades de Educação. In: SILVA, T. T. (Org.). Alienígenas na sala de aula: uma introdução aos estudos culturais em educação. Petrópolis: Vozes, 2001. p. 85-103.

HOOKS, B. Educação democrática. In: CÁSSIO, F. (Org.). Educação contra a barbárie: por escolas democráticas e pela liberdade de ensinar. São Paulo: Boitempo, 2019, p. 199-207.

IPEA - INSTITUTO DE PESQUISA ECONÔMICA APLICADA. Estudo do IPEA traça um perfil do trabalho doméstico no Brasil. IPEA, 2019. Disponível em: <https://bit.ly/3ceCoVL>. Acesso em: 2 jun. 2021.

KELLNER, D. Lendo imagens criticamente: em direção de uma pedagógica pós-moderna. In: SILVA, T. T. (Org.). Alienígenas na sala de aula: uma introdução aos estudos culturais em educação. Petrópolis: Vozes, 2001. p. 104-131.

LUZ, M. T. Novos saberes e práticas em saúde coletiva: estudo sobre racionalidades médicas e atividades corporais. São Paulo: Hucitec, 2007.

MARTIN, A. J.; STOCKLER, M. Quality of life assessment in health care research and practice. Evaluation \& Health Professions, Thousand Oaks, v. 21, n. 2, p. 141-156, jun. 1998.

MCLAREN, P. Multiculturalismo crítico. São Paulo: Cortez, 1997.

MCLAREN, P. Pedagogia da utopia. Santa Cruz do Sul: EdUNISC, 2001.

NEIRA, M. G. Ensino de educação física. São Paulo: Thomson Learning, 2007.

NELSON, C. et al. Estudos culturais: uma introdução. In: SILVA, T. T. (Org.). Alienígenas em sala de aula: uma introdução aos estudos culturais em educação. 3. ed. Petrópolis: Vozes, 2001. p. 7-38.

NERY, C. Extrema pobreza atinge 13,5 milhões de pessoas e chega a maior nível em 7 anos. Agência IBGE Notícias, [S.l.], 7 nov. 2019. Disponível em: <https://bit.ly/3zozzhl>. Acesso em: 2 jun. 2021.

OMS - ORGANIZAÇÃO MUNDIAL DA SAÚDE. Declaração de Alma-Ata sobre cuidados primários de saúde. Alma-Ata, 1978.

ONU - ORGANIZAÇÃO DAS NAÇÕES UNIDAS. Chefe da ONU destaca "crescimento horrível de violência doméstica” e pede cessar-fogo globalBR. Violência doméstica. 2020. Disponível em: <https://news.un.org/pt/story/2020/04/1709542>. Acesso em: 10 jun. 2020. 
PROPORÇÃO de mulheres e jovens na população médica cresce no Brasil: Demografia médica 2018. PEBMED, [S.l], 23 mar. 2018. Disponível em: <https://bit.ly/3cfY6qS>. Acesso em: 25 maio 2020.

SANTOMÉ, J. T. As culturas negadas e silenciadas no currículo. In: SILVA, T. T. (Org.). Alienígenas em sala de aula: uma introdução aos estudos culturais em educação. 3. ed. Petrópolis: Vozes, 2001. p. 159-177.

SUDRÉ, L. A crise tem rosto de mulher: elas são as mais afetadas pela precarização no país. Brasil de Fato, São Paulo, 8 mar. 2020. Disponível em: <https://bit.ly/3fJWbgv>. Acesso em: 25 maio 2020.

THE WHOQOL GROUP. Development of the WHOQOL: rationale and current status. International Journal of Mental Health, Ann Arbor, v. 23, n. 3, p. 24-56, 1994.

UNESCO - ORGANIZAÇÃO DAS NAÇÕES UNIDAS PARA A EDUCAÇÃO, A CIÊNCIA E A CULTURA. Global monitoring of school closures. 2020.

Disponível em: <https://en.unesco.org/covid19/ educationresponse\#schoolclosures $>$. Acesso em: 11 maio 2020.

\section{Contribuição dos autores}

Godoi e Novelli elaboraram e desenvolveram o projeto e escreveram o texto inicial deste relato de experiência. Kawashima contribuiu com a discussão teórica, com a redação e revisão do texto.

Recebido: 22/03/2021

Aprovado: 03/05/2021 